\title{
Analysis of Depth of Shade on Mercerized and Unmercerized Fabric among Different Woven Fabric Structures
}

\author{
Md Shamim Alam \\ Department of Textile Engineering, South East University, 251/A \& 252, Tejgaon I/A, Dhaka 1208, Bangladesh \\ Correspondence should be addressed to Md Shamim Alam; shamim100486@gmail.com
}

Received 23 June 2016; Accepted 21 August 2016

Academic Editor: Arunangshu Mukhopadhyay

Copyright ( 2016 Md Shamim Alam. This is an open access article distributed under the Creative Commons Attribution License, which permits unrestricted use, distribution, and reproduction in any medium, provided the original work is properly cited.

\begin{abstract}
The main objective of this paper is to analyze and compare the color strengths of mercerized and unmercerized fabric among different fabric structures. In this research work Remazol reactive dye and three types of woven fabrics were used such as $20 * 20$ sheeting, $30 * 30$ sheeting, and herringbone. Spectrophotometer was used to find out the amount of dye which is fixed in the fabrics after soap wash. Three different woven fabrics were dyed with reactive dye (Remazol Red, Remazol Yellow, and Remazol Blue) using pad dyeing method. It was found that mercerized fabric had higher depth of shade under the same dye concentration. In case of shade A $(0.5 \%) 20 * 20$ sheeting showed better color strength compared to other two structures but for shade B (1.5\%) and shade C (4\%) herringbone fabric showed better dye absorptive capacity than $20 * 20$ sheeting.
\end{abstract}

\section{Introduction}

Cotton fabrics are known to have been in use at least for 7000 years [1]. Today, cotton textiles represent more than half of the global textile market [2] and the demand is expected to continue [3]. This dominance of cotton fiber is mainly due to its natural comfort, performance, and appearance.

Preparation of cotton woven fabrics normally consists of singeing, desizing, scouring, and bleaching [4]. In most other cases, scouring and bleaching are the only preparation processes. For certain end uses, mercerizing is carried out. Singeing is the process of removing protruding fibers on the surface of the fabric. This process is omitted for certain enduse products such as flannel and velvet fabrics. Desizing is the process of removing the size on the most woven fabrics. Size is applied to reduce the frictional properties of warp yarns that improves weaving productivity by decreasing yarn breakages and increasing weft insertion speeds. Bleaching is done on cotton fabric to destroy the natural yellowish-brown colour of cotton fibers and the fibers' color turns into pure white.

Mercerization of cotton fabric is common practice in the preparation process that enhances dye uptake and facilitates uniform dyeing in addition to improving dimensional stability, strength, and luster [5]. Changes in microstructure, morphology, and conformation of the cellulose chains also occur during mercerization. The extent of the changes that occur depends on the processing time, caustic concentration, temperature, degree of polymerization, and source of cellulose, slack or tension treatment, the degree of applied tension during the treatment, and physical state of cellulose [6].

Pad-batch dyeing process is the most economical of all pad dyeing processes for the reactive dyeing of cotton [7]. In fact, for small lots of around 1000-10,000 meters, this process is more economical than exhaust dyeing, mainly due to minimal energy requirements. This process involves padding the fabric with a dye solution containing a suitable alkali system and then winding up the padded fabric onto a suitable roller [8].

In this work, an attempt was made to investigate the effect of mercerization as well as to observe the effect of color strength on mercerized and unmercerized fabric among different fabric structures. Three fabric structures were dyed with three different shade \% of Remazol reactive dye. Finally spectrophotometer was used to find out the strength of color on mercerized and unmercerized fabrics. 
TABLE 1: Different shade \% applied on different fabric structures.

\begin{tabular}{|c|c|c|c|c|c|c|}
\hline \multirow{2}{*}{ Shade \% } & \multicolumn{3}{|c|}{ Mercerized fabric } & \multicolumn{3}{|c|}{ Unmercerized fabric } \\
\hline & $20 \times 20$ sheeting & $30 \times 30$ sheeting & Herringbone & $20 \times 20$ sheeting & $30 \times 30$ sheeting & Herringbone \\
\hline Shade A $(0.5 \%)$ & $\sqrt{ }$ & $\sqrt{ }$ & $\sqrt{ }$ & $\sqrt{ }$ & $\sqrt{ }$ & $\sqrt{ }$ \\
\hline Shade B (1.5\%) & $\sqrt{ }$ & $\sqrt{ }$ & $\sqrt{ }$ & $\sqrt{ }$ & $\sqrt{ }$ & $\sqrt{ }$ \\
\hline Shade C (4\%) & $\sqrt{ }$ & $\sqrt{ }$ & $\sqrt{ }$ & $\sqrt{ }$ & $\sqrt{ }$ & $\sqrt{ }$ \\
\hline
\end{tabular}

\section{Experimental Methodology}

\subsection{Materials}

2.1.1. Fabrics. Three types of woven fabrics were taken, that is, $20 * 20$ sheeting, $30 * 30$ sheeting, and herringbone. These fabrics were collected from "Syntax Finishing Mills," BSCIC Station road, Tongi, Gazipur.

2.1.2. Instruments. Electric balance, scissor, beaker, sample dyeing machine, hot wash machine, pipette, squeezer machine, dryer and spectrophotometer with colour I match software, and so forth were used during this research work.

2.1.3. Dye Stuff and Chemicals. The chemicals and dye stuffs were collected from Syntax Finishing Mills, BSCIC Station road, Tongi, Gazipur. Reactive dye Remazol (Red, Blue, and Yellow), electrolyte (Gluber salt $\mathrm{Na}_{2} \mathrm{SO}_{4} \cdot 10 \mathrm{H}_{2} \mathrm{O}$ ), alkali (soda ash- $\mathrm{Na}_{2} \mathrm{CO}_{3}$ and caustic soda $\mathrm{NaOH}$ ), soaping agent (SW CONE), acetic acid (100\%), wetting agent and sequestering agent, and so forth were used.

\subsection{Methodology}

2.2.1. Sample Preparation. In this research work $100 \%$ cotton woven fabric was used that had been prepared from Syntax Finishing Mills. Here pretreatment like desizing, scouring, bleaching, and mercerization was done on the fabrics. $1 \%$ stock solution of Remazol red, yellow, and blue was prepared.

2.2.2. Procedure for Dyeing. At first, 9 pieces $(3 * 3)$ of mercerized fabrics and 9 pieces $(3 * 3)$ of unmercerized fabrics were taken. Three different shades (Table 1) were applied on mercerized and unmercerized fabrics.

Then the fabrics were dyed by using pad dyeing method with the help of lab dyeing machine where the liquor ratio was $1: 10$ for the mentioned shade percentage (see Table 1). During dyeing, standard methods were followed as prescribed by the manufacturers. The $\mathrm{pH}$ of the dye bath was adjusted by soda ash. We set the bath with substrate at room temperature $40^{\circ} \mathrm{C}$ and then added sample, dyes, soda ash, sequestering agent, wetting agent, anticreasing agent, leveling agent, and salt. Dyeing was done very quickly by pad dyeing machine. Total 18 fabric samples ( 9 mercerized and 9 unmercerized) were dyed by the same process. Then all the dyed samples were collected separately and covered with polybag and then put on the oven and kept for 30 mins for drying. After that we took the fabric after treatment. Then neutralization (by $1 \mathrm{~g} / \mathrm{L}$ acetic acid), soap wash (by $1 \mathrm{~g} / \mathrm{L}$ detergent), hot wash, and cold wash were done sequentially. Then fabric was squeezed
TABLE 2: Recipe used for dyeing.

\begin{tabular}{lcc}
\hline Shade A $(0.5 \%)$ & Shade B $(1.5 \%)$ & Shade C $(4 \%)$ \\
\hline Glauber salt $=20 \mathrm{~g} / \mathrm{L}$ & Glauber salt $=50 \mathrm{~g} / \mathrm{L}$ & Glauber salt $=70 \mathrm{~g} / \mathrm{L}$ \\
Soda ash $=5 \mathrm{~g} / \mathrm{L}$ & Soda $a s h=15 \mathrm{~g} / \mathrm{L}$ & Soda ash $=20 \mathrm{~g} / \mathrm{L}$ \\
\hline
\end{tabular}

Wetting agent: $1 \mathrm{~g} / \mathrm{L}$; leveling agent: $1 \mathrm{~g} / \mathrm{L}$; anticreasing agent: $1 \mathrm{~g} / \mathrm{L}$; material to liquor ratio $=1: 10$; temperature: $70^{\circ} \mathrm{C}$ (these parameters were used for three shades).

in the cold padder for $1 \mathrm{~min}$; at last calendaring was done on the fabric for 2 mins. Dyeing recipe for different shades of reactive dyes is given in Table 2 .

2.2.3. Measurement of Depth of Shade of Mercerized and Unmercerized Fabrics. The reflectance values at all wavelengths were measured by using a spectrophotometer. White mercerized and unmercerized fabrics were taken as standard and depth of shade was calculated using the built-in software of the computer color matching system.

2.2.4. Measurement of Color Fastness to Wash. ISO standards 105-C02 method was followed for wash fastness test. A specimen of $10 \times 4 \mathrm{~cm}$ was attached with a multifiber fabric strip. Washing solution containing $5 \mathrm{~g} / \mathrm{L}$ detergent was taken in the laboratory dyeing machine with a liquor ratio of $1: 50$. The specimen was treated for 45 minutes at $50 \pm 20^{\circ} \mathrm{C}$. The specimen was then removed and rinsed in normal water and dried in shadow. The change in color and degree of staining was evaluated visually using geometric grey scale given in Table 3.

\section{Results and Discussion}

Spectrophotometer was used to determine the color strength of mercerized and unmercerized fabrics individually. The effects of color strength on mercerized and unmercerized fabric with different fabric structures are discussed below sequentially.

3.1. Effect of Shade \% on Mercerized Fabric. Effects of different mercerized fabric structures and different shades are shown in the Table 3 and Figures 1-3. It was observed that, in case of shade A $(0.5 \%), 20 * 20$ sheeting fabric absorbed maximum dye compared to other two structures. Herringbone fabric absorbs more dye than $30 * 30$ sheeting fabric. So for light shade $(\mathrm{A}=0.5 \%), 20 * 20$ fabric is better than other two fabrics. Sequence of dye absorption for shade A $(0.5 \%)$ is $20 * 20$ sheeting $>$ herringbone $>30 * 30$ sheeting.

If we consider shade B (1.5\%) it was found that herringbone fabric absorbs maximum dye compared to other two 
TABLE 3: Effect of shade \% on mercerized fabric.

\begin{tabular}{ccccc}
\hline Shade $\%$ & Fabric structure & Dye at solution & Dye at fabric (depth of shade) & Dye loss \\
\hline \multirow{3}{*}{$\mathrm{A}=0.5$} & $20 \times 20$ sheeting & $0.5 \%$ & $0.36 \%$ & $0.14 \%$ \\
& $30 \times 30$ sheeting & $0.5 \%$ & $0.17 \%$ & $0.33 \%$ \\
& Herringbone & $0.5 \%$ & $0.31 \%$ & $0.19 \%$ \\
\hline \multirow{3}{*}{$\mathrm{B}=1.5$} & $20 \times 20$ sheeting & $1.5 \%$ & $0.08 \%$ & $0.42 \%$ \\
& $30 \times 30$ sheeting & $1.5 \%$ & $1.18 \%$ & $0.66 \%$ \\
\hline \multirow{4}{*}{$\mathrm{C}=4$} & Herringbone & $1.5 \%$ & $2.80 \%$ & $1.20 \%$ \\
& $20 \times 20$ sheeting & $4 \%$ & $2.1 \%$ & $1.90 \%$ \\
& $30 \times 30$ sheeting & $4 \%$ & $3.1 \%$ & $0.90 \%$ \\
\hline
\end{tabular}

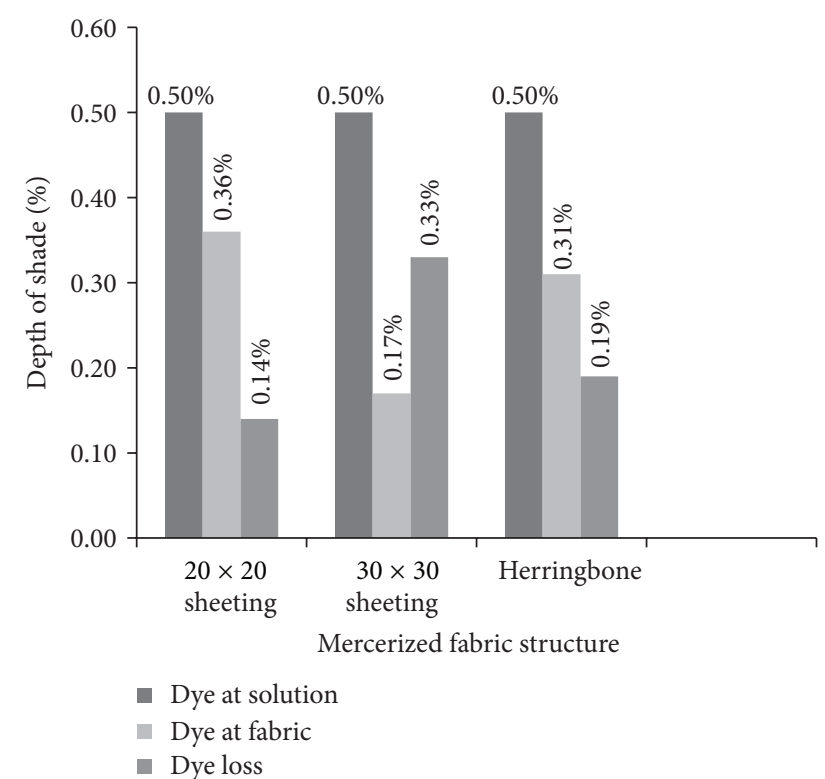

FIGURE 1: Effect of color strength on different mercerized fabric for $0.5 \%$ shade.

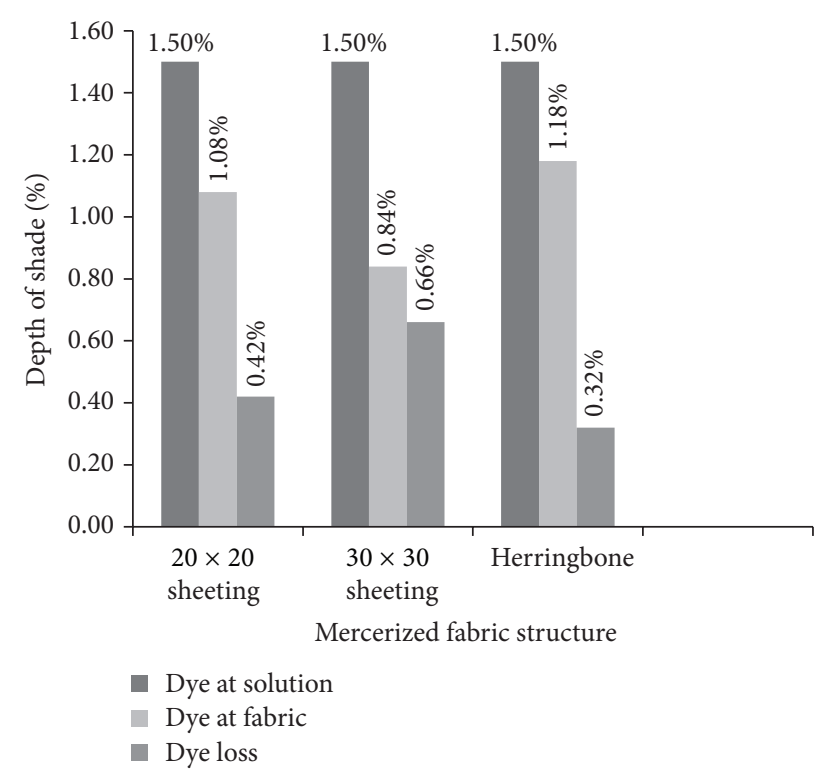

FIGURE 2: Effect of color strength on different mercerized fabric for $1.5 \%$ shade.

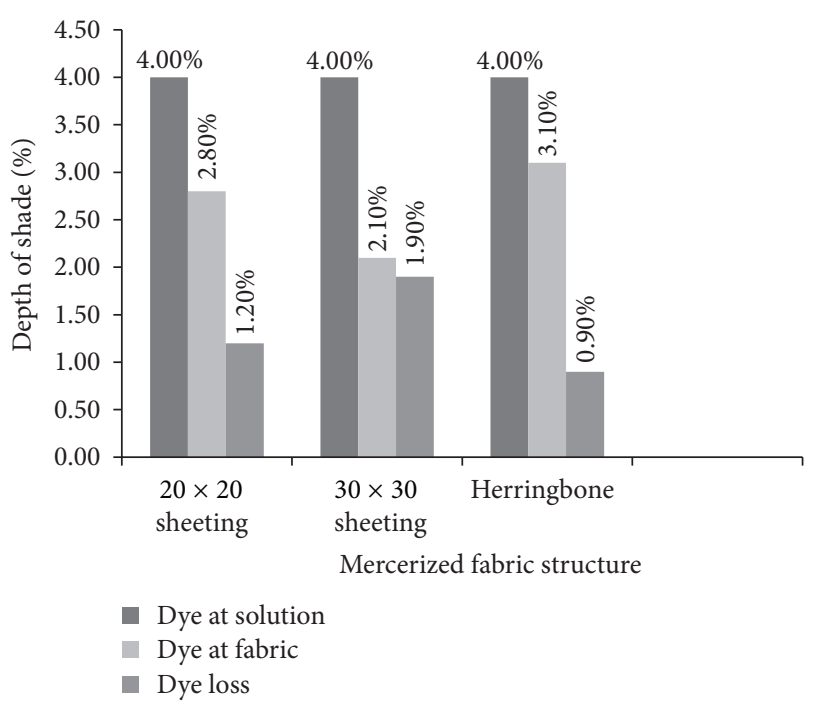

FIGURE 3: Effect of color strength on different mercerized fabric for $4 \%$ shade.

structures and dye loss \% of herringbone is less than other two structures. $20 * 20$ sheeting fabric absorbs more dye than $30 * 30$ sheeting fabric and in case of shade B (1.5\%) dye loss $\%$ of $30 * 30$ is more than other two structures. So for shade $\mathrm{B}(1.5 \%)$ sequence of dye absorption is herringbone $>20 * 20$ sheeting $>30 * 30$ sheeting.

Considering shade C (4\%) it was observed that herringbone fabric absorbs maximum dye compared to other two structures and dye loss \% of herringbone is less than other two structures. $20 * 20$ sheeting fabric absorbs more dye than $30 * 30$ sheeting fabric and in case of shade C (4\%) dye loss $\%$ of $30 * 30$ is more than other two structures. So for shade C ( $4 \%$ ) sequence of dye absorption is herringbone $>20 * 20$ sheeting $>30 * 30$ sheeting.

3.2. Effect of Shade \% on Unmercerized Fabric. Effects of different unmercerized fabric structures along with different shades are shown in the Table 4 and Figures 4-6. It was observed that, in case of shade A $(0.5 \%), 20 * 20$ sheeting fabric absorbs maximum dye compared to other two structures. Herringbone fabric absorbs more dye than $30 * 30$ sheeting fabric. So for light shade $(\mathrm{A}=0.5 \%) 20 * 20$ fabric is better 
TABLE 4: Effect of shade \% on unmercerized fabric.

\begin{tabular}{|c|c|c|c|c|}
\hline Shade \% & Fabric structure & Dye at solution & Dye at fabric (depth of shade) & Dye loss \\
\hline \multirow{3}{*}{$A=0.5$} & $20 \times 20$ sheeting & $0.5 \%$ & $0.28 \%$ & $0.22 \%$ \\
\hline & $30 \times 30$ sheeting & $0.5 \%$ & $0.14 \%$ & $0.36 \%$ \\
\hline & Herringbone & $0.5 \%$ & $0.16 \%$ & $0.34 \%$ \\
\hline \multirow{3}{*}{$B=1.5$} & $20 \times 20$ sheeting & $1.5 \%$ & $0.91 \%$ & $0.59 \%$ \\
\hline & $30 \times 30$ sheeting & $1.5 \%$ & $0.63 \%$ & $0.86 \%$ \\
\hline & Herringbone & $1.5 \%$ & $1.07 \%$ & $0.43 \%$ \\
\hline \multirow{3}{*}{$C=4$} & $20 \times 20$ sheeting & $4 \%$ & $1.75 \%$ & $2.25 \%$ \\
\hline & $30 \times 30$ sheeting & $4 \%$ & $1.64 \%$ & $2.36 \%$ \\
\hline & Herringbone & $4 \%$ & $1.87 \%$ & $2.13 \%$ \\
\hline
\end{tabular}

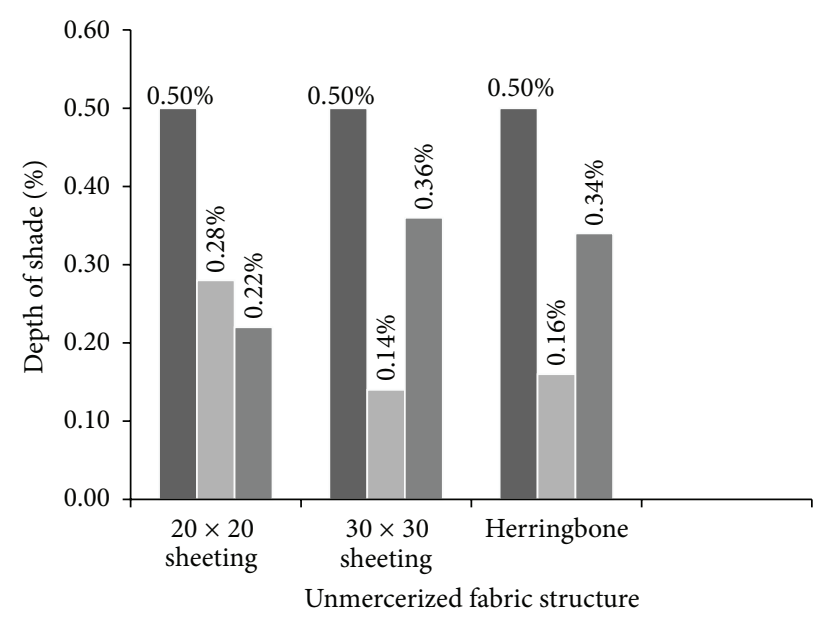

$$
\begin{aligned}
& \text { - Dye at solution } \\
& \text { - Dye at fabric } \\
& \text { - Dye loss }
\end{aligned}
$$

FIGURE 4: Effect of color strength on different unmercerized fabric for $0.5 \%$ shade.

than other two fabrics. Sequence of dye absorption for shade A $(0.5 \%)$ is $20 * 20$ sheeting $>$ herringbone $>30 * 30$ sheeting.

If we consider shade B $(1.5 \%)$ it was found that herringbone fabric absorbs maximum dye compared to other two structures and dye loss \% of herringbone is less than other two structures. $20 * 20$ sheeting fabric absorbs more dye than $30 *$ 30 sheeting fabric and in case of shade B (1.5\%) dye loss \% of $30 * 30$ is more than other two structures. So for shade B $(1.5 \%)$ sequence of dye absorption is herringbone $>20 * 20$ sheeting $>30 * 30$ sheeting. Considering shade C (4\%) it was observed that herringbone fabric absorbs maximum dye compared to other two structures and dye loss \% of herringbone is less than other two structures. $20 * 20$ sheeting fabric absorbs more dye than $30 * 30$ sheeting fabric and in case of shade C (4\%) dye loss $\%$ of $30 * 30$ is more than other two structures. So for shade C (4\%) sequence of dye absorption is herringbone $>20 * 20$ sheeting $>30 * 30$ sheeting.

3.3. Comparative Effects on Depth of Shade of Mercerized and Unmercerized Fabric. Comparative effects on different mercerized and unmercerized fabric structures and shades are shown in the Table 5 and Figures 7-9. In case of all the

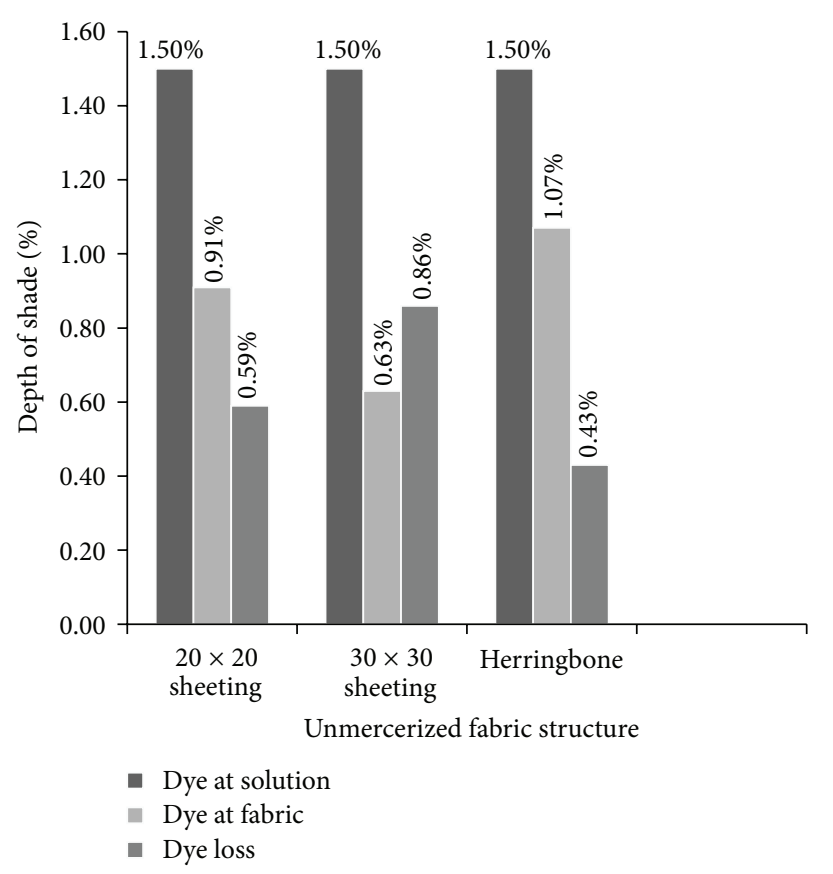

FIGURE 5: Effect of color strength on different unmercerized fabric for $1.5 \%$ shade.

shades it was found that depth of shade of mercerized fabric was better than unmercerized fabric. It was also observed that, in case of shade A $(0.5 \%), 20 * 20$ sheeting fabric absorbed maximum dye for both mercerized and unmercerized fabric compared to other two structures. Herringbone fabric absorbed more dye than $30 * 30$ sheeting fabric.

So for light shade $(\mathrm{A}=0.5 \%), 20 * 20$ fabric was better than other two fabrics.

In case of shade B (1.5\%) it was found that herringbone fabric absorbed the maximum dyestuffs for both mercerized and unmercerized fabric compared to the other two structures and dye loss \% of herringbone was less than those two structures. $20 * 20$ sheeting fabric absorbs more dye than $30 * 30$ sheeting fabric and in case of shade B (1.5\%) dye loss $\%$ of $30 * 30$ is more than other two structures.

Considering shade C (4\%) it was observed that herringbone fabric absorbed maximum dye for both mercerized and unmercerized fabric compared to other two structures and 
TABLE 5: Comparative results of mercerized and unmercerized fabric.

\begin{tabular}{ccccc}
\hline Shade $\%$ & Fabric structure & Dye at solution & Depth of shade of mercerized fabric & Depth of shade of unmercerized fabric \\
\hline \multirow{4}{*}{$\mathrm{A}=0.5$} & $20 \times 20$ sheeting & $0.5 \%$ & $0.36 \%$ & $0.28 \%$ \\
& $30 \times 30$ sheeting & $0.5 \%$ & $0.17 \%$ & $0.14 \%$ \\
& Herringbone & $0.5 \%$ & $0.31 \%$ & $0.16 \%$ \\
$\mathrm{~B}=1.5$ & $20 \times 20$ sheeting & $1.5 \%$ & $1.08 \%$ & $0.91 \%$ \\
& $30 \times 30$ sheeting & $1.5 \%$ & $0.84 \%$ & $0.63 \%$ \\
& Herringbone & $1.5 \%$ & $1.18 \%$ & $1.07 \%$ \\
$\mathrm{C}=4$ & $20 \times 20$ sheeting & $4 \%$ & $2.80 \%$ & $1.75 \%$ \\
& $30 \times 30$ sheeting & $4 \%$ & $2.1 \%$ & $1.64 \%$ \\
& Herringbone & $4 \%$ & $3.1 \%$ & $1.87 \%$ \\
\hline
\end{tabular}

TABLE 6: Rating of color fatness to wash.

\begin{tabular}{|c|c|c|c|c|c|c|c|c|}
\hline \multirow{2}{*}{ Fabric structure } & \multirow{2}{*}{ Shade \% } & \multicolumn{6}{|c|}{ Color staining } & \multirow{2}{*}{ Color change } \\
\hline & & Acetate & Cotton & Nylon & Polyester & Acrylic & Wool & \\
\hline \multirow{3}{*}{$20 * 20$ sheeting } & $0.5 \%$ & $4 / 5$ & $4 / 5$ & $4 / 5$ & $4 / 5$ & $4 / 5$ & $4 / 5$ & $4 / 5$ \\
\hline & $1.5 \%$ & $4-5$ & 4 & 4 & $4-5$ & 4 & 4 & 4 \\
\hline & $4 \%$ & 4 & 4 & 4 & 4 & 4 & 4 & 4 \\
\hline \multirow{3}{*}{$30 * 30$ sheeting } & $0.5 \%$ & $4 / 5$ & 4 & $4 / 5$ & $4 / 5$ & $4 / 5$ & $4 / 5$ & $4 / 5$ \\
\hline & $1.5 \%$ & $4 / 5$ & 4 & 4 & $4 / 5$ & 4 & 4 & 4 \\
\hline & $4 \%$ & 4 & 4 & 4 & 4 & 4 & 4 & 4 \\
\hline \multirow{3}{*}{ Herringbone } & $0.5 \%$ & $4 / 5$ & $4 / 5$ & $4 / 5$ & $4 / 5$ & $4 / 5$ & $4 / 5$ & 5 \\
\hline & $1.5 \%$ & $4 / 5$ & 4 & 4 & $4 / 5$ & 4 & 4 & 4 \\
\hline & $4 \%$ & 4 & 4 & 4 & 4 & 4 & 4 & 4 \\
\hline
\end{tabular}

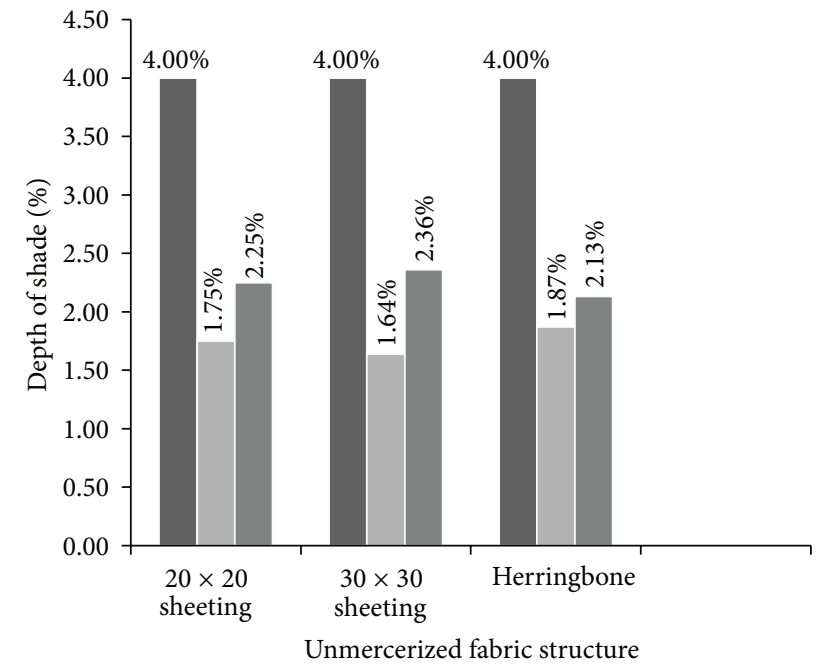

- Dye at solution

- Dye at fabric

- Dye loss

FIGURE 6: Effect of color strength on different unmercerized fabric for $4 \%$ shade.

dye loss $\%$ of herringbone was less than other two structures. $20 * 20$ sheeting fabric absorbed more dye than $30 * 30$ sheeting fabric and in case of shade C (4\%) dye loss \% of $30 * 30$ was more than other two structures.

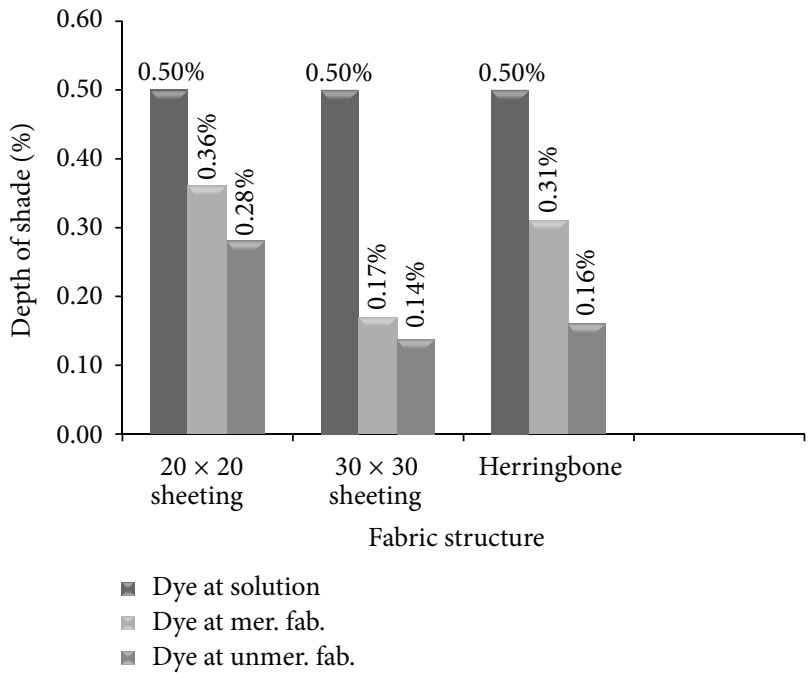

FIGURE 7: Effect of color strength on different mercerized and unmercerized fabric for $0.5 \%$ shade.

3.4. Analysis of Color Fastness to Wash. Reactive dyes on cellulose fiber have superior washing fastness property [9]. Here for all fabric structures and $0.5 \%$ shade, rating for color change was found to be $4 / 5$ to 5 that means good to excellent or excellent, which were shown in Table 6. In case of shade $1.5 \%$, color staining ratings were found to be $4 / 5$ to 4 that means good to excellent or good. In case of shade $4 \%$, color staining color change ratings were found to be 4 (good). The 


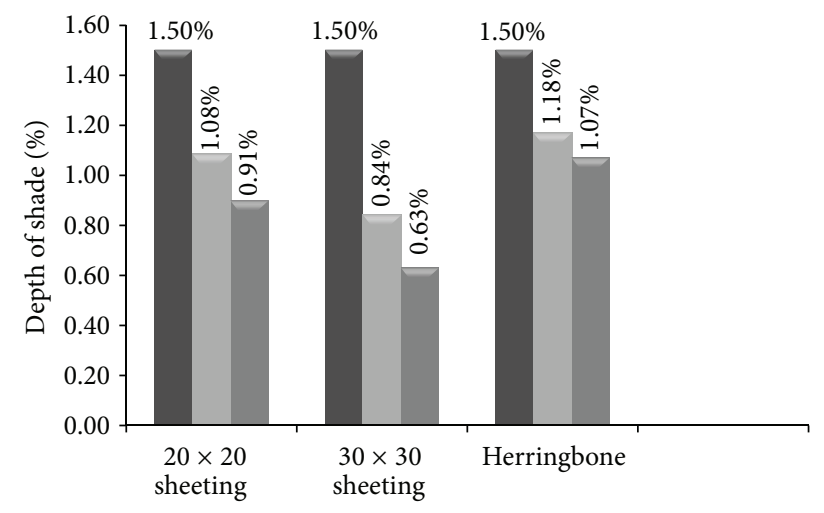

Fabric structure

$$
\begin{aligned}
& \text { Dye at solution } \\
& \text { Dye at mer. fab. } \\
& \text { Dye at unmer. fab. }
\end{aligned}
$$

FIGURE 8: Effect of color strength on different mercerized and unmercerized fabric for $1.5 \%$ shade.

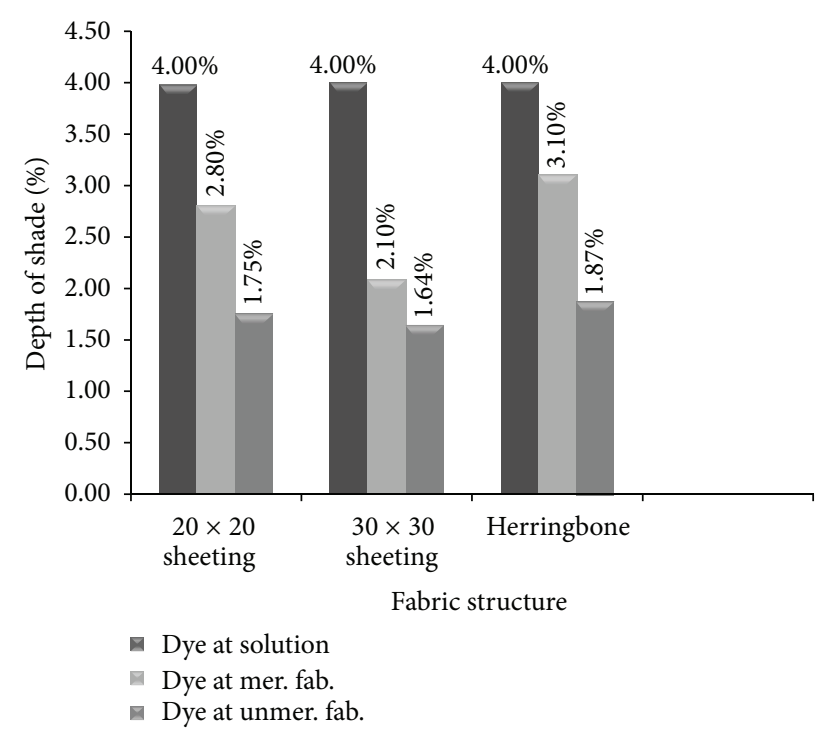

FIGURE 9: Effect of color strength on different mercerized and unmercerized fabric for $4 \%$ shade.

reason of good washing fastness in terms of both color change and color staining was due to the formation of chemical bonding (covalent bonds) between cotton polymer and dye molecules [10].

\section{Conclusion}

This study was planned to compare the depths of shade between mercerized and unmercerized fabric as well as to check the fastness properties among woven fabrics with different structures. In this research work it was found that, with the increment of shade \%, color fastness properties are affected for different fabric structures. Again it was also observed with the increment of shade \% of cotton woven fabric a considerable change on depth of color was found for different fabric structures. At last we can say that there is a considerable effect of fabric structure on depth of shade and color fastness when cotton woven fabrics were dyed with different shade $\%$, that is, $0.5 \%, 1.5 \%$, and $4 \%$. It can be concluded that herringbone fabric is better for both states: mercerized and unmercerized. Here mercerized fabric shows better depth of shade in reactive dyeing for all shades and all fabric structures.

\section{Competing Interests}

The author declares that there is no conflict of interests regarding the publication of this paper.

\section{References}

[1] “The story of cotton," 2010, https://www.cotton.org/pubs/ cottoncounts/story/index.cfm.

[2] S. Gordon and Y.-L. Hsieh, Cotton Science and Technology, Wood Head Publishing Limited, 2007.

[3] V. S. Borland, "King cotton: here today and here tomorrowfrom fiber to fashion, cotton weaves its way through the supply chain," Textile World, vol. 160, no. 3, 2010.

[4] W. S. Hickman, "Preparation in Cellulosic Dyeing," in Society of Dyers and Colorists, pp. 81-151, 1995.

[5] J. R. Aspland, "Practical application of reactive dyes," in Textile Chemist and Colorist, vol. 24, pp. 35-40, 1992.

[6] Broadbent, "Basic principles of textile coloration," in Society of Dyers and Colorists, pp. 332-357, 2005.

[7] J. Shore, "Dyeing with reactive dyes," in Cellulosic Dyeing, pp. 189-245, Society of Dyers and Colorists, 1995.

[8] Broadbent, "Basic principles of textile coloration," in Society of Dyers and Colorists, pp. 335-345, 2001.

[9] S. I. Kim, E. S. Lee, and H. S. Yoon, "Mercerization in degassed sodium hydroxide solution," Fibers and Polymers, vol. 7, no. 2, pp. 186-190, 2006.

[10] T. Haga and T. Takagishi, "Structural change in mercerized cotton fibers on cellulase treatment," Journal of Applied Polymer Science, vol. 80, no. 10, pp. 1675-1680, 2001. 

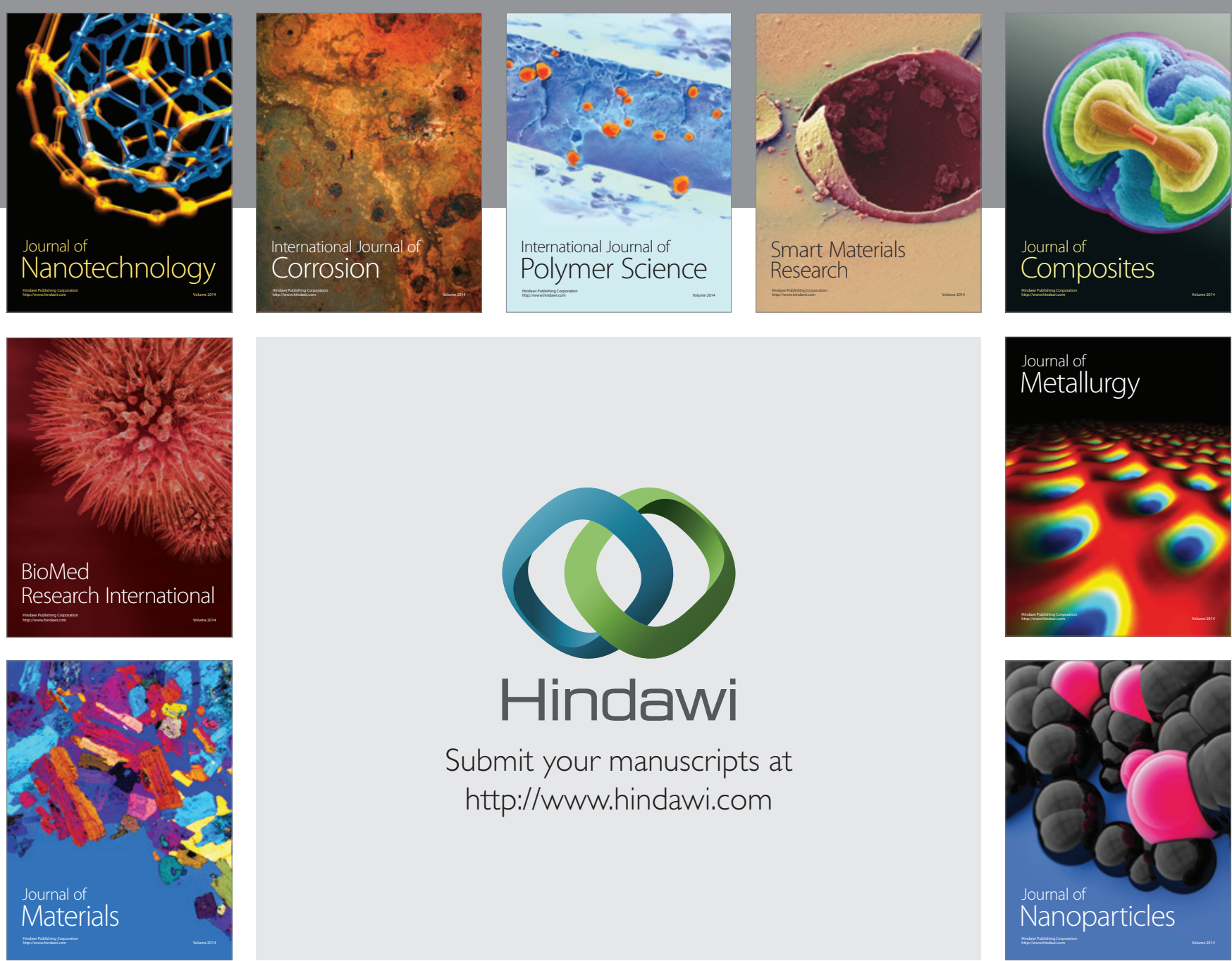

\section{Hindawi}

Submit your manuscripts at

http://www.hindawi.com

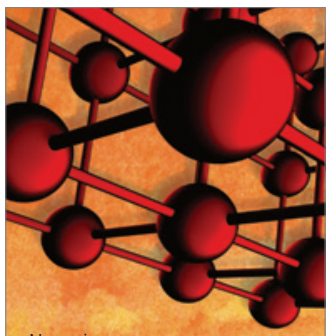

Materials Science and Engineering
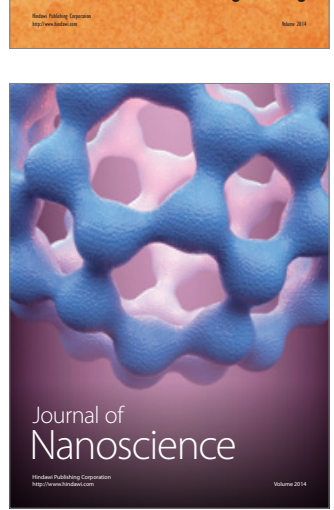
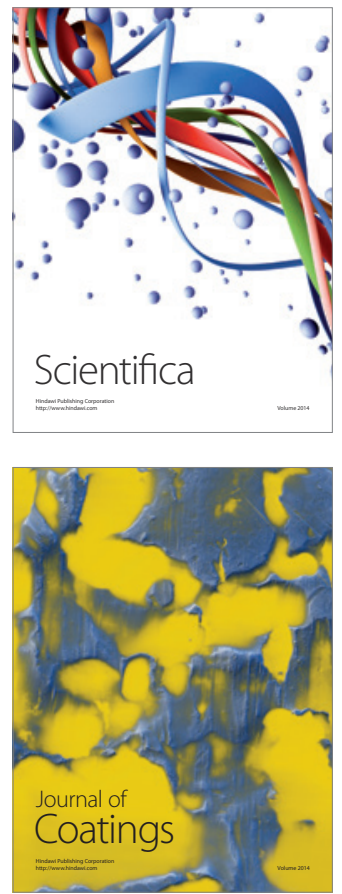
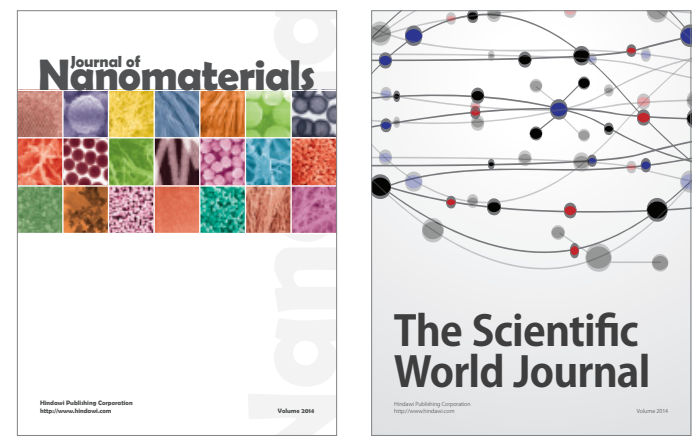

The Scientific World Journal
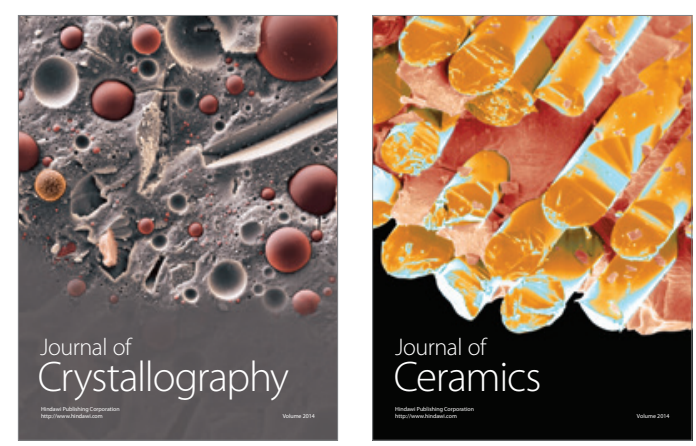
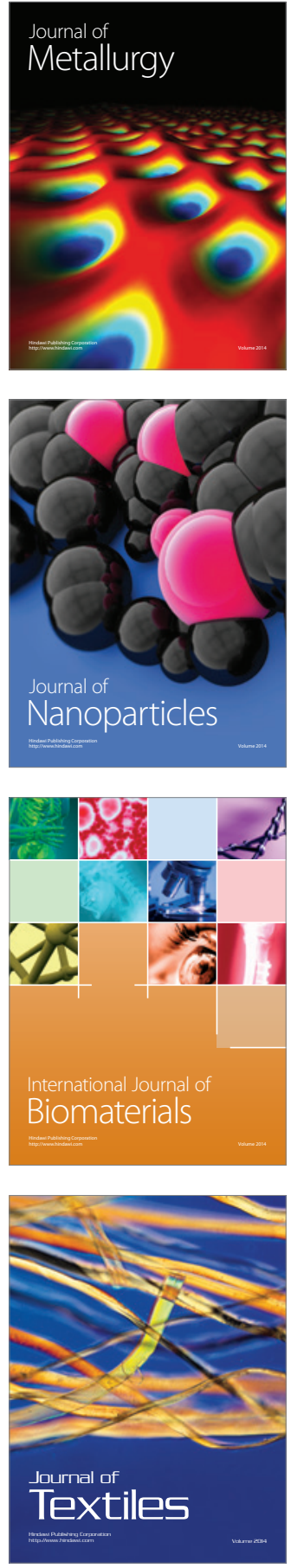